\title{
Deficit of mitochondria-derived ATP during oxidative stress impairs mouse MIl oocyte spindles
}

\author{
Xiao Zhang ${ }^{1,2, *}$, Xue Qing $\mathrm{Wu}^{1,3, *}$, Shuang $\mathrm{Lu}^{4,5,6}$, Ying $\mathrm{Lu} \mathrm{Guo}{ }^{1}, \mathrm{Xu} \mathrm{Ma}^{4,5,6}$ \\ ${ }^{1}$ Peking University First Hospital, Institute of Urology of Peking University, Beijing 100034, China, ${ }^{2}$ Reproductive and Genetic Center \\ of Peking University First Hospital, Beijing 100034, China; ${ }^{3}$ Department of Obstetrics and Gynecology, Shanxi Medical University \\ Second Hospital, Taiyuan 030000, China; ${ }^{4}$ Reproductive and Genetic Center of National Research Institute for Family Planning, \\ Beijing 100038, China: ${ }^{5}$ Department of Genetics, Peking Union Medical College, Beijing 100038, China: ${ }^{6}$ WHO Collaborative Center \\ for Research in Human Reproduction, Beijing 100038, China
}

Although the role of oxidative stress in maternal aging and infertility has been suggested, the underlying mechanisms are not fully understood. The present study is designed to determine the relationship between mitochondrial function and spindle stability in metaphase II (MII) oocytes under oxidative stress. MII mouse oocytes were treated with $\mathrm{H}_{2} \mathrm{O}_{2}$ in the presence or absence of permeability transition pores (PTPs) blockers cyclosporin A (CsA). In addition, antioxidant $N$-acetylcysteine (NAC), $\mathrm{F}_{0} / \mathrm{F}_{1}$ synthase inhibitor oligomycin A, the mitochondria uncoupler carbonyl cyanide 4-trifluoromethoxyphenylhydrazone (FCCP) or thapsigargin plus $2.5 \mathrm{mM} \mathrm{Ca}^{2+}\left(\mathrm{Th}+2.5 \mathrm{mM} \mathrm{Ca}^{2+}\right)$ were used in mechanistic studies. Morphologic analyses of oocyte spindles and chromosomes were performed and mitochondrial membrane potential $(\Delta \Psi \mathrm{m})$, cytoplasmic free calcium concentration $\left(\left[\mathrm{Ca}^{2+}\right]_{\mathrm{c}}\right)$ and cytoplasmic ATP content within oocytes were also assayed. In a time- and $\mathrm{H}_{2} \mathrm{O}_{2}$ dose-dependent manner, disruption of meiotic spindles was found after oocytes were treated with $\mathrm{H}_{2} \mathrm{O}_{2}$, which was prevented by pre-treatment with NAC. Administration of $\mathrm{H}_{2} \mathrm{O}_{2}$ led to a dissipation of $\Delta \Psi \mathrm{m}$, an increase in $\left[\mathrm{Ca}^{2+}\right]_{\mathrm{c}}$ and a decrease in cytoplasmic ATP levels. These detrimental responses of oocytes to $\mathrm{H}_{2} \mathrm{O}_{2}$ treatment could be blocked by pre-incubation with CsA. Similar to $\mathrm{H}_{2} \mathrm{O}_{2}$, both oligomycin A and FCCP dissipated $\Delta \Psi \mathrm{m}$, decreased cytoplasmic ATP contents and disassembled MII oocyte spindles, while high $\left[\mathrm{Ca}^{2+}\right]_{\mathrm{c}}$ alone had no effects on spindle morphology. In conclusion, the decrease in mitochondria-derived ATP during oxidative stress may cause a disassembly of mouse MII oocyte spindles, presumably due to the opening of the mitochondrial PTPs.

Cell Research (2006) 16:841-850. doi:10.1038/sj.cr.7310095; published online 19 September 2006

Keywords: spindle, oxidative stress, mitochondria, permeability transition pore, ATP

\section{Introduction}

It is well known that fertility senescence is concomitant with oocyte decay, which results in an increase in aneuploidy rate and a decline of pregnancy rate. A number of studies have suggested that both oocytic and embryonic

\footnotetext{
*These two authors contributed equally to this work. Correspondence: $\mathrm{Xu} \mathrm{Ma}$

Tel: +86-10-62176870; Fax: +86-10-62179059;

E-mail:genetic@263.net.cn

Received, 19 Mar 2006; revised 19 Jul 2006; accepted 10 Aug 2006; published online 19 Sep 2006
}

aneuploidies are closely associated with maternal age [1-3], although the underlying mechanisms responsible for the age-associated aneuploidies remain to be elucidated.

Normally, mature mammalian oocytes can be temporarily arrested at the metaphase II (MII) stage of the second meiotic division where chromosomes are equatorially localized in the meiotic spindle of oocytes, a dynamic structure composed of microtubule (MT) bundles that are polar polymers of $\alpha$ - and $\beta$-tubulin heterodimers. The rate of meiotic division errors increases corresponding to maternal aging, which leads to non-extrusion of the first polar body, shrunken size of spindles, irregular distribution of chromosomes and occurrence of aneuploidies. Recent 
studies indicate that maternal aging is accompanied by the generation of oxidative stress in oocytes [4-7], suggesting that oxidation may contribute to the age-related increase in the rate of meiotic division errors and aneuploidies. Tarin has proposed a mechanism based on 'the oxygen radical-mitochondrial injury hypothesis of aging' to explain the effects of aging on mammalian oocytes $[7,8]$. This hypothesis has been partially supported by several studies demonstrating the role of oxidants in regulating MT polymerization and cytoskeleton re-formation [9]. In addition, antioxidants can protect meiotic divisions from disorders that occur either in an oxidative stress situation or during maternal aging [10-12], further demonstrating that oxidative stress is involved in fertility senescence.

The involvement of oxidation in the age-related increase in meiotic division errors and aneuploidies prompts a role of mitochondria in maternal aging. As a source of reactive oxygen species (ROS) generated from the 'leakage' of high-energy electrons along the electron transport channels $[13,14]$, mitochondria are meanwhile a vulnerable target of ROS. Attack originated from free oxygen radicals can damage the mitochondrial DNA of quiescent oocytes and lead to the loss of their intrinsic mitochondrial function [15-17]. The mitochondrial function is suggested to play a major role in controlling fertility aging [18] and the activity of mitochondria in both oocytes and pre-implanted embryos appears to be inversely correlated with maternal aging and embryo development $[19,20]$. For example, lower $\Delta \Psi \mathrm{m}$ in disordered mitochondria leads to abnormalities of oocyte meiotic apparatus, resulting in chaotic mosaicisms of embryos [21]. In addition, the interactions of mitochondrial DNA, proteins or lipids with ROS cause a decline of glutathione (GSH)/glutathione disulfide ratio [7], which may affect the stability of oocyte spindles. Furthermore, the oxidative phosphorylation within mitochondria provides a major source of ATP needed for mature MII oocytes that consume high levels of ATP [22]. Sufficient high-energy substrates are required for several cellular events during fertilization, including polymerization of MTs, activation of motor proteins and cell cycle regulation kinases, segregation of chromosomes and calcium oscillations [22, 23]. Over-reaction with ROS, however, cannot generate but consumes ATP, resulting in a decrease in ATP levels within oocytes and further leading to mitochondrial dysfunction.

Although previous studies suggest that oxidation affects mitochondria function and meiotic spindle integrity, the linkage between the latter two events is not established. We hypothesize that responses to ROS may damage mitochondria in either quiescent or maturing oocytes and that dysfunction of mitochondria, a situation in which ATP output is significantly reduced, interferes with the forma- tion of meiotic apparatus (e.g., causing the instability of oocyte spindles) and leads to aneuploidies during maternal aging. In the present study, using $\mathrm{H}_{2} \mathrm{O}_{2}$ to generate an oxidative stress condition, we examined the alternations of mitochondria function in MII mouse oocytes, as measured by $\Delta \Psi \mathrm{m}$, cytoplasmic ATP content and $\left[\mathrm{Ca}^{2+}\right]$, and analyzed the changes of both oocytic spindle and chromosome morphology. Our results suggest that the decrease in mitochondria-derived ATP induced by oxidative stress via permeability transition pore (PTP) opening causes a disassembly of mouse MII oocyte spindles, providing experimental evidence supporting our above hypothesis.

\section{Materials and Methods}

\section{Chemicals, reagents and animal models}

All chemicals and reagents were purchased from Sigma (St Louis, MO, USA), unless otherwise specified. To induce superovulation, six-week-old NIH female mice were injected intraperitoneally with pregnant mare serum gonadotropin (10 IU per mouse), and $48 \mathrm{~h}$ later, with human chorionic gonadotropin (hCG, $10 \mathrm{IU}$ per mouse). The animals were killed by cervical dislocation at $12.5-13 \mathrm{~h}$ after $\mathrm{hCG}$ injection. The animal care and use protocol was approved by the institutional committee of Peking University First Hospital.

\section{Oocyte collection and culture}

Oocyte-rich cells enclosed in cumulus masses were harvested from the ampullae with potassium simplex-optimized medium (KSOM) [24] containing $14 \mathrm{mM}$ of HEPES and $300 \mathrm{IU}$ of hyaluronidase. With gentle washes by pipetting, interstitial tissues within cumulus were removed and cumulus-free oocytes were collected and cultured in KSOM. Oocytes showing polar bodies were identified as MII oocytes, under a bright field microscope. The MII oocytes were further grown in KSOM supplemented with $10 \%$ fetal calf serum and mineral oil at $37^{\circ} \mathrm{C}$ in a humidified $5 \% \mathrm{CO}_{2}$ atmosphere.

\section{Analyses of spindle structure and chromosome configu- ration}

After treatment with various reagents or combinations as detailed below, MII oocytes were immunocytofluorescently stained to reveal oocyte spindles using a modified protocol previously described by Baka et al. [25]. Briefly, oocytes were fixed for $30 \mathrm{~min}$ in an MTstabilizing buffer containing $2.0 \%$ paraformaldehyde, permeabilized for $60 \mathrm{~min}$ in $0.2 \%$ Triton X-100 buffer and then stored in phosphate-buffered saline (PBS) containing $1 \mu \mathrm{M}$ of taxol at $4{ }^{\circ} \mathrm{C}$. For immunostaining, samples were incubated with a blocking solution composed of $2 \%$ bovine serum albumin and $2 \%$ normal goat serum for $10 \mathrm{~min}$ and reacted in PBS with a goat anti-mouse $\alpha$-tubulin monoclonal antibody (mAb, 1:500 dilution) at $37{ }^{\circ} \mathrm{C}$ for $1 \mathrm{~h}$. To detect binding of the primary $\mathrm{mAb}$, a fluorescein isothiocyanate (FITC)-conjugated anti-goat immunoglobulin G (1:100 dilution) was added and then incubated at $37^{\circ} \mathrm{C}$ for $30 \mathrm{~min}$. Chromosomes were further counterstained by propidium iodide $(20 \mu \mathrm{g} / \mathrm{ml})$ for 15 min. After staining, oocytes were mounted onto glass slides, onto which an anti-fade Vectashield mounting medium (H-1000, Vector Laboratories Inc., Burlingame, CA, USA) was added. Coverslips were dropped over the specimens and sealed with clear nail varnish. 
The slides were viewed under a laser-scanning confocal microscope (LSCM, Olympus Fluoview FV300, Olympus) equipped with argon and helium-neon lasers (excitation wavelength: 488 and $543 \mathrm{~nm}$, respectively) and the images were analyzed using the Olympus FV1000 (Ver 1.3) and Adobe Photoshop 6.0 software.

Each spindle was examined at intervals of $1 \mu \mathrm{m}$, and projections of varying thicknesses were obtained by compiling multiple consecutive images after computerized processing. Only those spindles which that lay in a horizontal plane were evaluated for oocyte spindle length (pole-to-pole distance) and width. Dispersed chromosome distributions were defined as one or more individual chromosomes and were separated from the chromosomal plate by a distance greater than or equal to chromosomal length [10].

\section{Measurement of $\Delta \Psi m$}

To monitor $\Delta \Psi \mathrm{m}$ changes, MII oocytes were incubated in culture medium at $37^{\circ} \mathrm{C}$ for $15 \mathrm{~min}$ with $0.5 \mu \mathrm{M}$ tetramethylrhodamine methyl ester (TMRM, Molecule Probes, Eugene, OR, USA), a membrane-permeable cationic fluorophore that accumulates electrophoretically into mitochondria in response to their negative potential. After two washes with $\mathrm{KSOM}$, cells were incubated at $37^{\circ} \mathrm{C}$ before mounting onto the microscope stage for further treatment as described below. Samples were analyzed using an LSCM equipped with helium-neon lasers (excitation wavelength: $543 \mathrm{~nm}$ ) in a time-lapse mode. Single scans through the mid-level of oocytes were imaged and saved for further measurement of fluorescence intensity. Laser power and photo-multiplier settings were kept constant for the entire experiment.

\section{Measurement of cytoplasmic ATP contents}

ATP contents in the cytoplasm were measured by an ATP assay kit (Bioluminescent Somatic Cell Assay Kit, St Louis, MO, USA) following the protocol described by Van Blerkom et al. [20]. Briefly, 50 oocytes per group were stored at $-80^{\circ} \mathrm{C}$ in $200 \mu 1$ of ultra-purified water. For ATP measurement, $50 \mu 1$ of thawed sample solution was added to $100 \mu \mathrm{l}$ of ice-cold cell ATP-releasing reagent for $5 \mathrm{~min}$ on ice prior to adding $100 \mu 1$ of ice-cold ATP assay mix (1:25 diluted in assay mix buffer). The reaction mixture was then incubated for $5 \mathrm{~min}$ in the dark at room temperature to allow an initial chemiluminescence flash period. Bioluminescence of each sample was measured using a high-sensitivity luminometer (TurnerBiosystems Luminometer Model TD-20/20, TurnerBiosystems, Sunnyvale, CA, USA). Sample ATP contents were calculated using a standard curve generated from 11 ATP gradient concentrations ranging from 5 fmol to 5 pmol.

\section{Measurement of cytosolic free $\mathrm{Ca}^{2+}$ concentration}

The concentrations of cytosolic free $\mathrm{Ca}^{2+}$ were measured by using Fluo-3 AM as an indicator. In brief, oocytes were incubated in H-KSOM supplemented with $10 \%$ fetal calf serum and $5 \mu \mathrm{M}$ Fluo-3AM at $37^{\circ} \mathrm{C}$ for $15 \mathrm{~min}$. After washing, oocytes were seeded in Petri dishes with a glass bottom, at $37^{\circ} \mathrm{C}$. Depending on experiment purposes, different reagents were added to elicit or inhibit $\mathrm{Ca}^{2+}$ signals and cells were observed under an SLCM. Fluorochromes were excited with an argon laser (excitation wavelength: $488 \mathrm{~nm}$ ) and emission signals were captured via an FITC filter. Cells were scanned at a 15-min interval under a time-lapse mode and imaged at mid-level sections. The relative fluorescence intensity, which reflects the concentration of free $\mathrm{Ca}^{2+}$ in oocyte cytosolic, was generated on the basis of the formula $\left(F-F_{\min }\right) /\left(F_{\max }-F_{\min }\right)$, where $F_{\max }$ represents the maximum fluorescence intensity obtained when oocytes were stimulated by $1 \mu \mathrm{M} \mathrm{A} 23187$ and $F_{\min }$ indicates the minimum fluorescence intensity obtained from the A23187-treated oocytes in the presence of $3 \mathrm{mM}$ of EGTA.

\section{Statistical analysis}

One- and two-way analysis of variance was applied for comparisons of means. Chi-square test was applied for comparisons of frequencies. The level of significance was set at $p<0.01$, unless otherwise indicated.

\section{Results}

$\mathrm{H}_{2} \mathrm{O}_{2}$-induced disruption of MII oocyte spindle and its suppression by cyclosporin A (CsA) or $\mathrm{N}$-acetylcysteine (NAC)

To examine changes in spindle morphology and chromosome alignment under oxidative stress conditions, oocytes were treated with $\mathrm{H}_{2} \mathrm{O}_{2}$ at various concentrations in the presence or absence of CsA or NAC and then analyzed under a confocal microscope after fluorescent staining. CsA, which is a specific inhibitor of cyclophilin D, a matrix-localized protein of the mitochondrial permeability pore complex, can prevent PTPs opening. NAC, which is a known antioxidant, can scavenge ROS effectively.

As shown in Figure 1 and Table 1, in a both time- and $\mathrm{H}_{2} \mathrm{O}_{2}$ dose-dependent manner, exposure of MII oocytes to $\mathrm{H}_{2} \mathrm{O}_{2}$ resulted in a decrease in the size of cellular spindles,

Table 1 Effects of $\mathrm{H}_{2} \mathrm{O}_{2}$ on length and width of MII spindles and on percentage of abnormally dispersed chromosomes in mouse oocytes

\begin{tabular}{lllll}
\hline Treatment with $\mathrm{H}_{2} \mathrm{O}_{2}$ & No. of oocytes & Spindle length $(\mu \mathrm{m})^{*}$ & Spindle width $(\mu \mathrm{m})^{*}$ & Dispersed chromosomes \\
\hline $0 \mu \mathrm{M}$ (control) h & 27 & $26.6 \pm 1.3^{\mathrm{a}}$ & $15.6 \pm 0.5^{\mathrm{a}}$ & $3.7(1)^{\mathrm{a}}$ \\
$50 \mu \mathrm{M} 1 \mathrm{~h}$ & 27 & $15.4 \pm 1.7^{\mathrm{b}}$ & $10.6 \pm 1.0^{\mathrm{b}}$ & $11(3)^{\mathrm{a}}$ \\
$100 \mu \mathrm{M} 1 \mathrm{~h}$ & 27 & $9.9 \pm 1.5^{\mathrm{c}}$ & $4.2 \pm 0.8^{\mathrm{c}}$ & $14.8(4)^{\mathrm{a}}$ \\
$100 \mu \mathrm{M} 1.5 \mathrm{~h}$ & 27 & $0.0^{\mathrm{d}}$ & $0.0^{\mathrm{d}}$ & $41(11)^{\mathrm{b}}$ \\
\hline
\end{tabular}

Values with different superscript letters within the same column differ significantly $(p<0.01)$.

${ }^{*}$ Values are means \pm SD.

Pooled data from three replicates. 

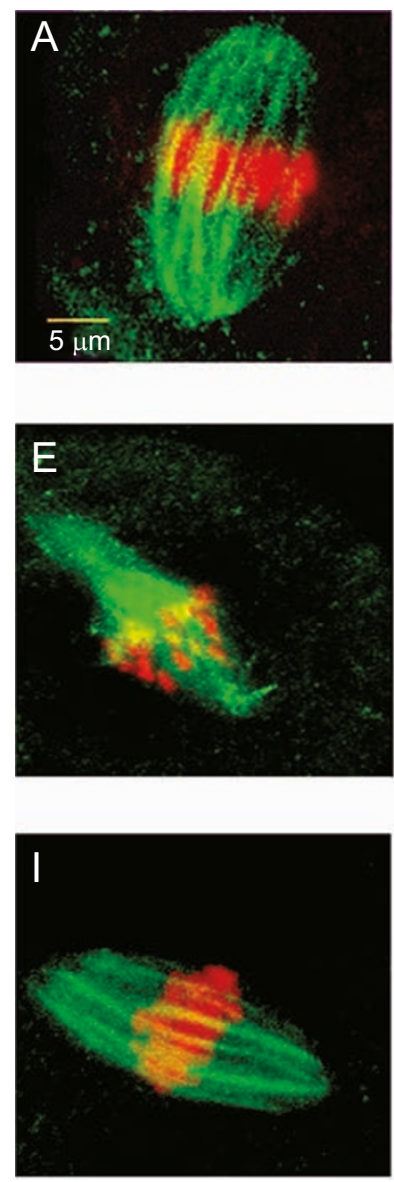
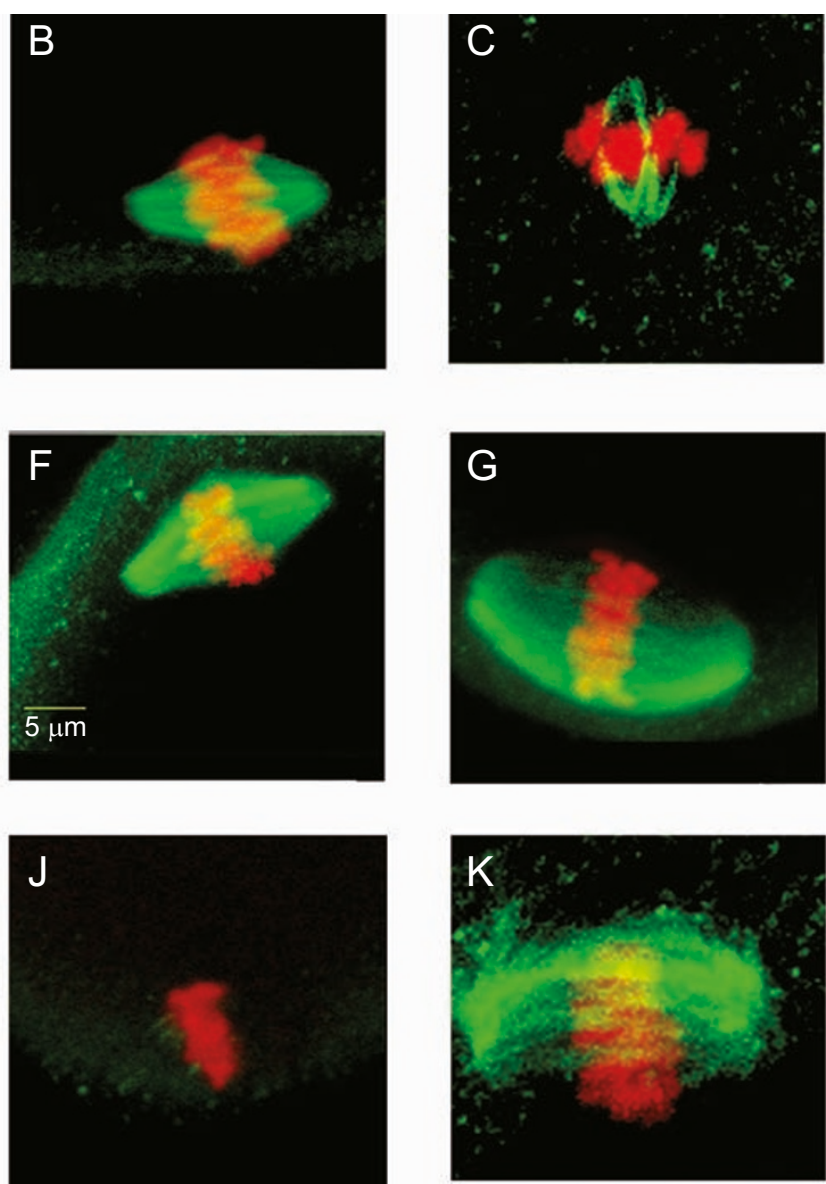
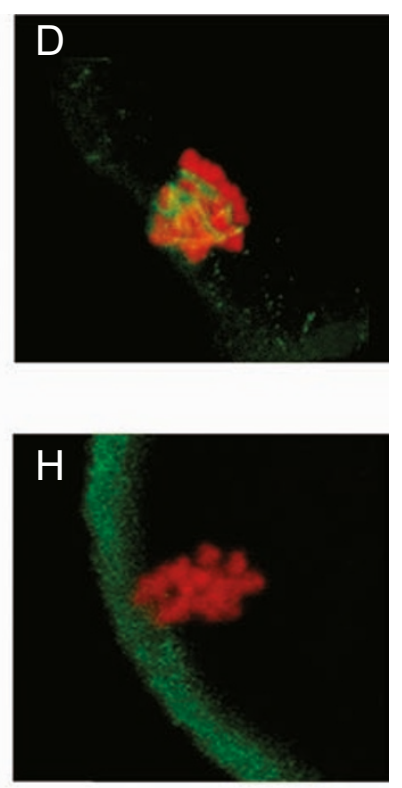

Figure 1 Morphology of spindles and chromosomes within mouse MII oocytes observed by a confocal laser scanning microscope. Images were captured by an LSCM after samples were fluorescently stained. In control oocytes, cultured in KSOM medium, spindles demonstrated a barrel-like shape and chromosomes aligned regularly (A). After treatment with $50 \mu \mathrm{M} \mathrm{H}_{2} \mathrm{O}_{2}$ for $1 \mathrm{~h}$, spindles appeared to be shrunk (B and $\mathbf{C}$ ). A completely disorganized spindle with dispersed chromosomes was observed in the presence of $100 \mu \mathrm{M}$ $\mathrm{H}_{2} \mathrm{O}_{2}$ for $1.5 \mathrm{~h}$ (D). The oocyte recovered for $1 \mathrm{~h}$ after treatment with $1.5 \mathrm{~h} \mathrm{H}_{2} \mathrm{O}_{2}(100 \mu \mathrm{M})$ showed abnormal spindle shape and misalignment of chromosomes (E). However, spindle shrinkage induced by treating cells with $\mathrm{H}_{2} \mathrm{O}_{2}$ for 1 h could be partially inhibited when cells were pre-incubated with $10 \mu \mathrm{M}$ CsA (F). A more pronounced phenomenon, of which normal barrel shapes of spindles remained in NAC-treated oocytes, was observed even though cells were exposed to $100 \mu \mathrm{M} \mathrm{H}_{2} \mathrm{O}_{2}$ (G). In addition, oligomycin A (2.5 $\mu \mathrm{M})(\mathbf{H})$ totally disrupted spindles while high $\left[\mathrm{Ca}^{2+}\right]_{\mathrm{c}}$ induced by $\mathrm{Th}+2.5 \mathrm{mM} \mathrm{Ca}{ }^{2+}$ had no significant effect on the shape of oocyte spindles (I). The oocyte recovered for $1 \mathrm{~h}$ after treatment with $1 \mathrm{~h} \mathrm{H}_{2} \mathrm{O}_{2}(1 \mathrm{mM})$ showed disrupted spindle (J). Oocytes treated with $5 \mu \mathrm{M} \mathrm{H}_{2} \mathrm{O}_{2}$ for $2 \mathrm{~h}$ showed no significant alteration in the size of spindle (K).

including both spindle length (pole-to-pole distance) and width, and disruption of the alignment of meiotic oocyte chromosomes. The spindles displayed a characteristic barrel-like shape and regular chromosomes were observed in the control MII oocytes incubated in $\mathrm{H}_{2} \mathrm{O}_{2}$-free KSOM (Figure 1A). In contrast, the spindles of oocytes treated with $50 \mu \mathrm{M} \mathrm{H}_{2} \mathrm{O}_{2}$ for $1 \mathrm{~h}$ exhibited significant decreases in both length and width (Table 1; Figure 1A and 1B). More remarkable changes in spindles were found in oocytes treated with $100 \mu \mathrm{M} \mathrm{H}_{2} \mathrm{O}_{2}$ for $1 \mathrm{~h}$ (Figure 1C). However, those spindles still kept their barrel-like shapes and the corresponding chromosomes localized properly at the mid- plane of spindles. After oocytes were exposed to $100 \mu \mathrm{M}$ $\mathrm{H}_{2} \mathrm{O}_{2}$ for $1.5 \mathrm{~h}$, however, the morphological shape of their spindles was totally disrupted and the rate of abnormally dispersed chromosomes was significantly increased (Figure 1D, Table 1). Interestingly, the disrupted spindles, which were induced by incubation with $100 \mu \mathrm{M} \mathrm{H}_{2} \mathrm{O}_{2}$ for $1.5 \mathrm{~h}$, were restored by $81 \%(n=37)$ with dispersed chromosomes (90\%) at $1 \mathrm{~h}$ after removal of $\mathrm{H}_{2} \mathrm{O}_{2}$ from the culture medium (Figure 1E). Furthermore, few disrupted spindles $(19 \%, n=21)$ could be recovered when cells were treated with $1 \mathrm{mM} \mathrm{H}_{2} \mathrm{O}_{2}$ for $1 \mathrm{~h}$ (Figure $1 \mathrm{~J}$ ). No apparent spindle disruptions were detected in MII oocytes $(n=20)$ after a 2 -h 
exposure to $5 \mu \mathrm{M} \mathrm{H}_{2} \mathrm{O}_{2}$ (Figure $1 \mathrm{~K}$ ).

To further explore the mechanisms involved in spindle disruption after $\mathrm{H}_{2} \mathrm{O}_{2}$ challenge, CsA or NAC was administrated before oocytes were exposed to $\mathrm{H}_{2} \mathrm{O}_{2}$. Oocytes were stimulated with $100 \mu \mathrm{M} \mathrm{H}_{2} \mathrm{O}_{2}$ following pre-incubation of cells with $10 \mu \mathrm{M}$ CsA for $20 \mathrm{~min}$. Pre-incubation of cells with CsA partially reversed the lesion of meiotic spindles induced by $\mathrm{H}_{2} \mathrm{O}_{2}$ (Figures $1 \mathrm{~F}$ and 2 ). As expected, meiotic spindles totally avoided being impaired when oocytes were pre-incubated with $10 \mu \mathrm{g} / \mathrm{ml} \mathrm{NAC}$ for $30 \mathrm{~min}$ and then cotreated with $100 \mu \mathrm{M} \mathrm{H}_{2} \mathrm{O}_{2}$ (Figures $1 \mathrm{G}$ and 2), comparing with the control group.

$\mathrm{H}_{2} \mathrm{O}_{2}$-induced mitochondrial dysfunction (collapse of $\Delta \Psi m$, increase of $\mathrm{Ca}^{2+}$ release, and decrease of ATP production) suppressed by CsA

To further investigate the influence of oxidants on mitochondrial function, mitochondrial membrane potential $(\Delta \Psi \mathrm{m}),\left[\mathrm{Ca}^{2+}\right]_{\mathrm{c}}$ and ATP content were assayed after oocytes were treated with $\mathrm{H}_{2} \mathrm{O}_{2}$ in the presence or absence of CsA. The $\Delta \Psi \mathrm{m}$ was dynamically measured at various times with a 15-min interval in terms of the relative intensity of the fluorescence indicator, TMRM, after oocytes were stimulated with $50 \mu \mathrm{M}$ or $100 \mu \mathrm{M} \mathrm{H}_{2} \mathrm{O}_{2}$ following pre-incubation with $10 \mu \mathrm{M}$ CsA for $20 \mathrm{~min}$. As shown in Figure 3A(b) and $3 \mathrm{~B}, \mathrm{H}_{2} \mathrm{O}_{2}$ depressed the fluorescence signals emitted from TMRM in a both time- and $\mathrm{H}_{2} \mathrm{O}_{2}$ dose-dependent

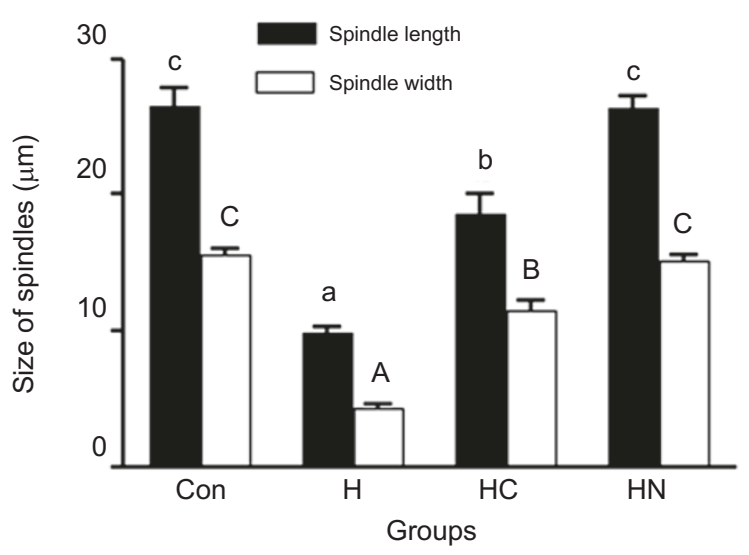

Figure 2 Both CsA and NAC prevent $\mathrm{H}_{2} \mathrm{O}_{2}$-induced spindle shrinkage. $\mathrm{H}_{2} \mathrm{O}_{2}$ exposure leads to a decrease in spindle length and width that was partially prevented by CsA and totally prevented by NAC. Con, control oocytes cultured in KSOM; H, oocytes treated with $100 \mu \mathrm{M} \mathrm{H}_{2} \mathrm{O}_{2}$ for $1 \mathrm{~h}$; HC, oocytes pre-incubated with $10 \mu \mathrm{M} \mathrm{CsA}$ for 20 min prior to $1-\mathrm{h}_{2} \mathrm{O}_{2}(100 \mu \mathrm{M})$ treatment; $\mathrm{HN}$, oocytes pre-incubated with $10 \mu \mathrm{g} / \mathrm{ml}$ NAC prior to $1-\mathrm{h}_{2} \mathrm{O}_{2}(100 \mu \mathrm{M})$ treatment. Data were presented as means $\pm \mathrm{SD}$. Different superscripts for bars within the same category indicate a significant difference $(p<0.01)$. manner, indicating that oocyte $\Delta \Psi \mathrm{m}$ depolarized progressively following exposure to $\mathrm{H}_{2} \mathrm{O}_{2}$. Pre-incubation with CsA could effectively prevent $\Delta \Psi \mathrm{m}$ loss induced by $\mathrm{H}_{2} \mathrm{O}_{2}$ (Figure 3B). The validity of TMRM, which was used as a fluorescence indicator of $\Delta \Psi \mathrm{m}$, was verified by using a mitochondria uncoupler, carbonyl cyanide 4-trifluoromethoxyphenylhydrazone (FCCP, $2 \mu \mathrm{M}$ ), which could rapidly disrupt mitochondria and totally eliminate TMRM signals as expected [Figure $3 \mathrm{~A}(\mathrm{c})$ and $3 \mathrm{~B}$ ]. To determine the changes in oocyte $\left[\mathrm{Ca}^{2+}\right]$, oocytes underwent a process similar to that in the experiments for detecting $\Delta \Psi \mathrm{m}$. As shown in Figure 4, the addition of $\mathrm{H}_{2} \mathrm{O}_{2}$ into KSOM gradually increased oocyte $\left[\mathrm{Ca}^{2+}\right]_{\mathrm{c}}$. In addition, the elevation of $\left[\mathrm{Ca}^{2+}\right]_{\mathrm{c}}$ was $\mathrm{H}_{2} \mathrm{O}_{2}$ dose-dependent. CsA, a specific
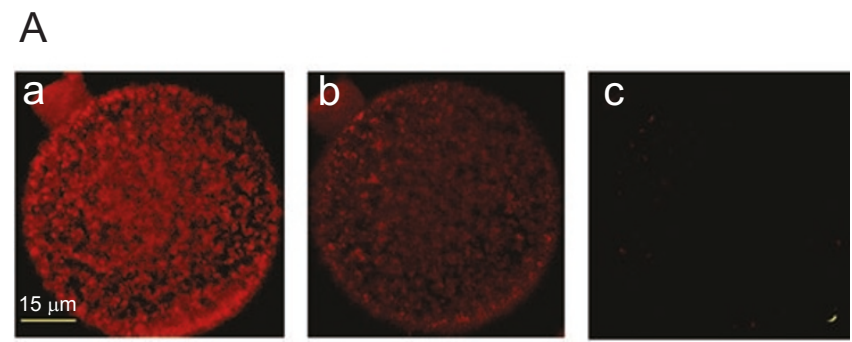

\section{B}

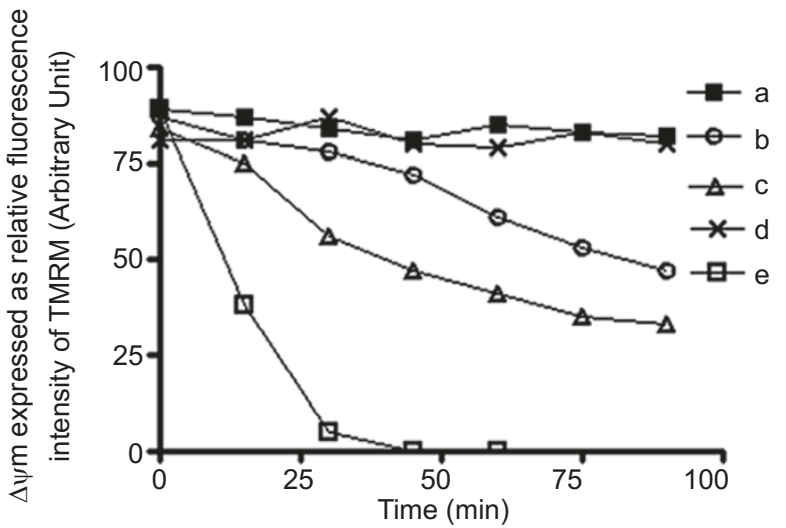

Figure 3 Effects of $\mathrm{H}_{2} \mathrm{O}_{2}$ on MII oocyte $\Delta \Psi \mathrm{m}$. Mitochondria membrane potential $(\Delta \Psi \mathrm{m})$ of MII oocytes were indicated by changes of TMRM fluorescence intensity, which was measured by an LSMC as detailed in Materials and Methods. (A)Representative images of MII oocytes cultured in $\mathrm{KSOM}$ as control (a), treated with $50 \mu \mathrm{M}$ of $\mathrm{H}_{2} \mathrm{O}_{2}$ for $1 \mathrm{~h}(\mathrm{~b})$ or FCCP $(2 \mu \mathrm{M})$ for $30 \mathrm{~min}(\mathrm{c})$. Quantitative analysis of TMRM fluorescence intensity was performed by an LSCM under a time-lapse mode and data were shown in (B). (a) Oocytes cultured in KSOM as control; (b) treated with $50 \mu \mathrm{M} \mathrm{H}_{2} \mathrm{O}_{2}$; (c) treated with $100 \mu \mathrm{M} \mathrm{H}_{2} \mathrm{O}_{2}$; (d) oocytes pre-incubated with $10 \mu \mathrm{M}$ CsA for 20 min prior to $\mathrm{H}_{2} \mathrm{O}_{2}(100 \mu \mathrm{M})$; (e) treated with $2 \mu \mathrm{M}$ FCCP. Data of TMRM fluorescence intensity (arbitrary units) for each time point were obtained from 4 to 7 oocytes. 


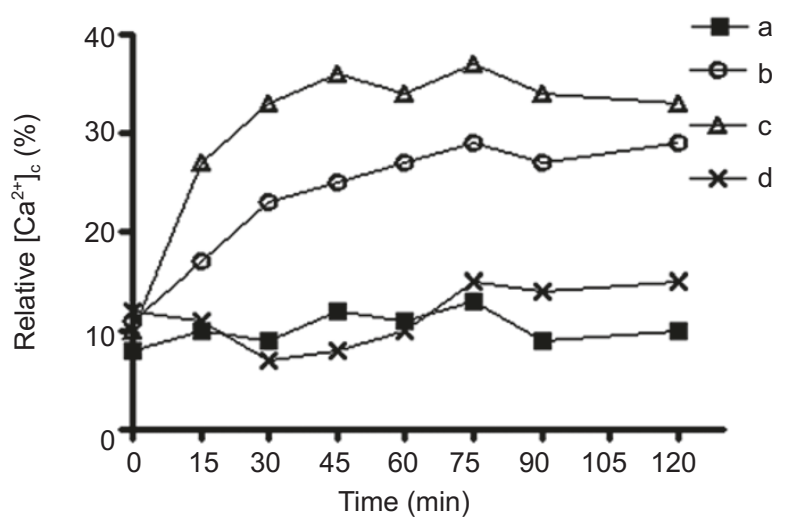

Figure 4 Effects of $\mathrm{H}_{2} \mathrm{O}_{2}$ on relative $\left[\mathrm{Ca}^{2+}\right]_{\mathrm{c}}$ in oocytes. Relative $\left[\mathrm{Ca}^{2+}\right]_{\mathrm{c}}$ was calculated by the formula $\left.\left(F-F_{\min }\right)\right) /\left(F_{\max }-F_{\min }\right)$, in which $F$ represents fluorescence intensity (as detailed in the Materials and Methods). (a) Oocytes cultured in KSOM as control; (b) treated with $50 \mu \mathrm{M} \mathrm{H}_{2} \mathrm{O}_{2}$; (c) treated with $100 \mu \mathrm{M} \mathrm{H}_{2} \mathrm{O}_{2}$; (d) oocytes pre-incubated with $10 \mu \mathrm{M}$ CsA for 20 min prior to $\mathrm{H}_{2} \mathrm{O}_{2}(100 \mu \mathrm{M})$. The data for each group at each time point were obtained from 4 to 7 replicates.

PTP inhibitor, significantly suppressed the calcium signals elicited by $\mathrm{H}_{2} \mathrm{O}_{2}$, although it could not restore $\left[\mathrm{Ca}^{2+}\right]_{\mathrm{c}}$ to the control level at the end of our experiment.

We next determined the effect of $\mathrm{H}_{2} \mathrm{O}_{2}$ on ATP production. As shown in Figure 5, ATP content was significantly lower in oocytes treated with $\mathrm{H}_{2} \mathrm{O}_{2}$ for $1 \mathrm{~h}$ than that in controls. Pre-treatment with CsA maintained cellular ATP concentrations at the control level. Furthermore, both FCCP (a mitochondrial uncoupler $(2 \mu \mathrm{M})$ ) and oligomycin (an F0/F1 synthase inhibitor $(2.5 \mu \mathrm{M})$ ) could dramatically reduce ATP level in MII oocytes (Figure 5). These results raise the possibility that ATP content rather than $\left[\mathrm{Ca}^{2+}\right]_{\mathrm{c}}$ may have a crucial role in $\mathrm{H}_{2} \mathrm{O}_{2}$-induced disruption of spindle structure.

Disruption of meiotic spindle correlates with changes of ATP content but not $\left[\mathrm{Ca}^{2+}\right]_{c}$

Since exposure of oocytes to $\mathrm{H}_{2} \mathrm{O}_{2}$ increased intracellular $\mathrm{Ca}^{2+}$ signals while impairing the integrity of cellular spindles, we next investigated whether intracellular $\mathrm{Ca}^{2+}$ levels affect oocytic spindle structure.

We emptied the calcium stores within oocytes by using thapsigargin (Th) $(10 \mu \mathrm{M})$, an inhibitor against the endoplasmic reticulum $\mathrm{Ca}^{2+}$ ATPase (SERCA), which activates $\mathrm{Ca}^{2+}$ influx through the store-operated $\mathrm{Ca}^{2+}$ entry, and then incubated cells in KSOM containing $2.5 \mathrm{mM}$ $\mathrm{Ca}^{2+}$ for $1 \mathrm{~h}$ to introduce a high level of cytoplasmic free calcium (Figure 6). High $\left[\mathrm{Ca}^{2+}\right]_{\mathrm{c}}$ established by the addition of extraneous $\mathrm{Ca}^{2+}$ had no effect on either ATP level (Figure 5) or meiotic spindle structure ( $n=12$; Figure 1I).

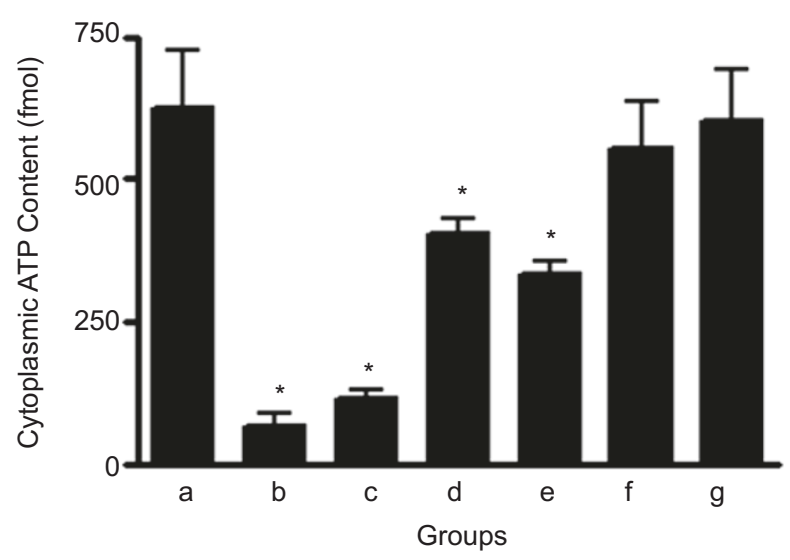

Figure 5 Effects of $\mathrm{H}_{2} \mathrm{O}_{2}$, FCCP, oligmycin A, CsA and high $\left[\mathrm{Ca}^{2+}\right]_{\mathrm{c}}$ on ATP levels in oocytes. Oocytes were treated with different reagents as indicated in the graph and ATP levels were detected by a special assay kit as described in Materials and Methods. (a) Oocyte incubated in KSOM as control; (b) treated with $2 \mu \mathrm{M}$ FCCP for 20 min; (c) treated with $2.5 \mu \mathrm{M}$ oligmycin A for $20 \mathrm{~min}$; (d) treated with $50 \mu \mathrm{M} \mathrm{H}_{2} \mathrm{O}_{2}$ for $1 \mathrm{~h}$; (e) treated with $100 \mu \mathrm{M} \mathrm{H}_{2} \mathrm{O}_{2}$ for $1 \mathrm{~h}$; (f) preincubated with $10 \mu \mathrm{M}$ CsA for 20 min prior to $1-\mathrm{h}_{2} \mathrm{O}_{2}(100 \mu \mathrm{M})$ treatment; $(\mathrm{g})$ incubated in KSOM with high calcium $(2.5 \mathrm{mM})$ and $10 \mu \mathrm{M} \mathrm{Th}+2.5 \mathrm{mM} \mathrm{Ca}$ for $1 \mathrm{~h}$. Data were presented as means $\pm \mathrm{SD}$. In comparison to the control, a significant difference of ATP level was indicated by asterisks: ${ }^{*} p<0.01$.

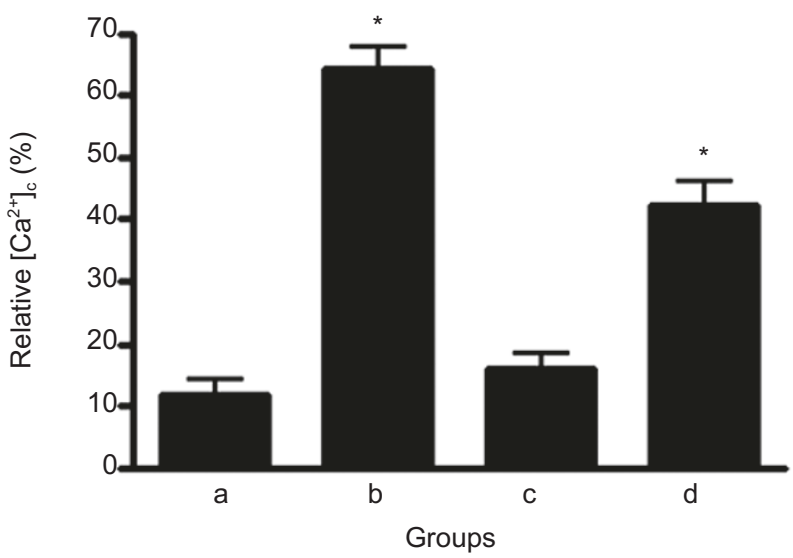

Figure 6 Effects of FCCP, oligmycin A and $\mathrm{Th}+2.5 \mathrm{mM} \mathrm{Ca}^{2+}$ on relative $\left[\mathrm{Ca}^{2+}\right]_{\mathrm{c}}$ in oocytes. Oocytes were treated with different reagents listed in the graph and relative $\left[\mathrm{Ca}^{2+}\right]_{\mathrm{c}}$ was worked out according to changes of fluorescence intensity of the $\mathrm{Ca}^{2+}$ indicator, Fluo-3AM as described in Materials and Methods. (a) Oocyte incubated in KSOM as control; (b) treated with $2 \mu \mathrm{M}$ FCCP for 20 min; (c) treated with $2.5 \mu \mathrm{M}$ oligmycin A for $20 \mathrm{~min}$; (d) incubated in KSOM with high calcium $(2.5 \mathrm{mM})$ and $10 \mu \mathrm{M}$ Th $(\mathrm{Th}+2.5 \mathrm{mM}$ $\mathrm{Ca}$ ) for $20 \mathrm{~min}$. Data were presented as means \pm SD. In comparison to the control, a significant difference of $\left[\mathrm{Ca}^{2+}\right]_{\mathrm{c}}$ level was indicated by asterisks: ${ }^{*} p<0.01$. 
FCCP, a mitochondria uncoupler, also induced a high concentration of intracellular $\mathrm{Ca}^{2+}$ (Figure 6), but significantly reduced the cytoplasmic ATP contents (Figure 5). All the spindles were totally disrupted ( $n=12)$ (figure not shown). In addition, exposure of oocytes to oligomycin $\mathrm{A}(2.5 \mu \mathrm{M})$ for 20 min did not affect $\left[\mathrm{Ca}^{2+}\right]_{\mathrm{c}}$. However, oligomycin A dramatically suppressed cytoplasmic ATP level (Figure 5) and completely damaged the integrity of oocytic spindles $(n=12$, Figure 1H). The effects of oligomycin and FCCP on spindle structure were reversible after withdrawal of those inhibitors (data not shown).

\section{Discussion}

Oocytes at the MII stage have an obvious advantage for studying spindle biological behavior since all bivalents of spindles in arrested MII oocytes usually precisely position at the equatorial plane. Studies have suggested that oocytic spindles at the MII stage are more sensitive to oxidants or spindle-specific positions than those at other stages [26, 27]. In the present study, we employed mouse MII oocytes as a model to investigate the effects of oxidants on spindles. Our data support the notion that oxidative stress induces mitochondrial dysfunction and spindle disruption in MII mouse oocytes. We found that as an oxidant, $\mathrm{H}_{2} \mathrm{O}_{2}$ exerted a detrimental effect on oocytic spindles in a time- and $\mathrm{H}_{2} \mathrm{O}_{2}$ dose-dependent manner, which is consistent with the results obtained by using other forms of ROS such as diamide and tertiary butyl hydroperoxide $[27,28]$. The major damage to spindles following exposure of oocytes to $\mathrm{H}_{2} \mathrm{O}_{2}$ was shown by the changes in the pole-to-pole distance and the equatorial width of spindles and the integrity of spindles. These data endorse Tarin's oxidative stress hypothesis regarding the potential effects of age-associated oxidative stress on mammalian oocytes [7].

Interestingly, the changes in the size of oocytic meiotic spindles under oxidative stress seem to be more sensitive than that in their shape. Following challenge with a lower dose of $\mathrm{H}_{2} \mathrm{O}_{2}(50 \mu \mathrm{M})$, both spindles and chromosomes maintain their normal shape and regular alignment, while their size was distinctly decreased. However, the structure of spindles was totally disrupted with an increasing rate of dispersed chromosomes, after the oocytes were treated with $100 \mu \mathrm{M} \mathrm{H}_{2} \mathrm{O}_{2}$ for $1.5 \mathrm{~h}$. At this level of oxidative treatment, those alterations are still reversible. In contrast, the damage to the integrity of spindles and alignment of chromosomes was irreversible after cells were incubated with a more intensive concentration of $\mathrm{H}_{2} \mathrm{O}_{2}(1 \mathrm{mM})$. It is generally believed that normally spindles link to chromosomes via kinetochores and any force derived from spindle shrinkage can be passed forward to chromosomes and may lead to their re-arrangement. As shown in the present study, the alteration of spindle size did not affect chromosomes on their alignment and dispersed chromosomes appeared only if the integrity of spindles had completely been broken down after exposure to high levels of $\mathrm{H}_{2} \mathrm{O}_{2}$. These data provided further evidence supporting the fact that aggregation or dispersal of chromosomes is determined by integrity of spindles.

To further investigate the mechanism by which oxidative stress affects meiotic spindle structure, we pre-treated oocytes with CsA and found that CsA could partially but effectively reverse the detrimental effects of $\mathrm{H}_{2} \mathrm{O}_{2}$ on spindles. It is well known that CsA can prevent PTP opening. For this reason, CsA is widely employed in studies concerning $\Delta \Psi \mathrm{m}$ dissipation and cell apoptosis which occurred in somatic cells $[29,30]$. With respect to the relationship between CsA and spindles, currently there are few studies to address the question of whether CsA can exert any effect on spindle structure and function. Based on our present data, we believe that it is by blocking PTPs within oocyte mitochondria that CsA produces a protective effect against spindle impairment induced by $\mathrm{H}_{2} \mathrm{O}_{2}$, since in our parallel experiments, pre-incubation of cells with CsA before $\mathrm{H}_{2} \mathrm{O}_{2}$ challenge could prevent $\Delta \Psi \mathrm{m}$ loss, ATP reduction and $\left[\mathrm{Ca}^{2+}\right]_{\mathrm{c}}$ increase, results similar to those obtained in studies using CsA as a PTP inhibitor $[29,30]$. The data from the present study further reinforce the fact that normal mitochondria function is essential to maintaining the integrity of the MT network and meiotic apparatus including spindles [23,31]. As a source of ROS, mitochondria is meanwhile a well-known vulnerable target of ROS and its responses to oxidative stress have been investigated in various fields, especially in studying oocytes and embryos during apoptosis, fertility and development [32-34], supporting the theory that free oxygen radicals induce aging [35-37]. Our present results demonstrate that dysfunction of oocytic mitochondria, which is directly caused by oxidants via opening mitochondrial PTPs, may further impair the ability of oocytes to form normal meiotic apparatuses. To a certain extent, these results may explain why embryo mosaicism and retardance occur in embryo development during fertility aging, although this was not tested in the present study.

Since normal mitochondria function is required for the formation of oocytic spindles, we next examined the pathways through which oxidant-induced mitochondrial dysfunction mediates spindle impairment. Metabolic inhibitors such as FCCP and oligmycin A, and Th+2.5 mM $\mathrm{Ca}^{2+}$ were used to introduce a condition with a low ATP level and/or a high $\left[\mathrm{Ca}^{2+}\right]_{\mathrm{c}}$, situations that are frequently seen with $\mathrm{H}_{2} \mathrm{O}_{2}$-induced mitochondrial dysfunction. Similar to those in $\mathrm{H}_{2} \mathrm{O}_{2}$-stimulated oocytes, high $\mathrm{Ca}^{2+}$ signals were also captured after cells were incubated with $\mathrm{Th}+2.5 \mathrm{mM}$ 
$\mathrm{Ca}^{2+}$. However, $\mathrm{Th}+2.5 \mathrm{mM} \mathrm{Ca}^{2+}$ alone did not significantly alter the ATP level and the spindle structure within oocytes. This result seems to be inconsistent with other reports that, both in vitro $[38,39]$ and in vivo $[40]$, an increase of $\left[\mathrm{Ca}^{2+}\right]_{\mathrm{c}}$ would prevent polymerization of dimeric tubulins and cause rapid depolymerization of pre-formed MTs. One potential explanation for this controversy is that the cytosolic $\mathrm{Ca}^{2+}$ signals $\left(10^{-7} \mathrm{M}\right)$ elicited by either $\mathrm{H}_{2} \mathrm{O}_{2}$ or $\mathrm{Th}+2.5 \mathrm{mM} \mathrm{Ca}^{2+}$ are relatively weak, compared to the levels that can mediate MT depolymerization [32]. $\left[\mathrm{Ca}^{2+}\right]_{\mathrm{c}}$ required for depolymerizing MTs is indeed quite variable. As observed by other groups, MT depolymerization occurs if $\left[\mathrm{Ca}^{2+}\right]_{\mathrm{c}}$ ranges from $10^{-5}$ to $10^{-3} \mathrm{M}[1,3,6,41,42]$, a dose level that could not be reached by using either $\mathrm{H}_{2} \mathrm{O}_{2}$ or $\mathrm{Th}+2.5 \mathrm{mM} \mathrm{Ca}^{2+}$ as stimuli. Furthermore, response of MTs to $\mathrm{Ca}^{2+}$ seems to be cell type dependent. For instance, tubulin within Ehrlich ascites tumor cells has virtually no sensitivity to $\mathrm{Ca}^{2+}$ at all [43]. An alternative explanation is that oocytic spindles have an ability to resist $\mathrm{Ca}^{2+}$ signals sparked by either $\mathrm{H}_{2} \mathrm{O}_{2}$ or $\mathrm{Th}+2.5 \mathrm{mM} \mathrm{Ca}^{2+}$. As we know, either formation or disorganization of spindles is dependent on the cooperation of motor proteins, capping proteins, MT-associated proteins and microtubulin. In the early 1990s, Gorbsky et al.[44] found that MTs in the metaphase-arrested mouse oocytes could turn over rapidly, suggesting that spindles are highly dynamic. The contribution of $\mathrm{Ca}^{2+}$ to MT depolymerization in an oxidative stress situation could be diluted due to the rapid turnover of MTs in the MII spindles, even though $\mathrm{Ca}^{2+}$ plays a critical role in the formation of normal spindles in MI oocytes [41].

As mentioned above, a significant decrease in cytoplasmic ATP content was observed in $\mathrm{H}_{2} \mathrm{O}_{2}$-challenged MII oocytes accompanying the enhancement of $\left[\mathrm{Ca}^{2+}\right]_{c}$. This observation raised the question of whether energy deficit contributed to spindle disruption during oxidative stress. To address this question, we employed the mitochondrial uncoupler FCCP and the F0/F1 synthase inhibitor oligomy$\operatorname{cin} \mathrm{A}$ to interfere with oocytic mitochondria function and found that both these inhibitors could result not only in a dissipation of $\Delta \Psi \mathrm{m}$ but also a decrease of ATP level and an impairment of spindle structure; all these were consistent with the other results from $\mathrm{H}_{2} \mathrm{O}_{2}$-stimulated oocytes. Our present data demonstrated that ATP molecules within the resting MII oocytes were at a high turnover rate. Generation of mitochondria-derived ATP and consumption of local ATP must be elaborately balanced for cell survival $[22,23]$. Therefore, an appropriate $\Delta \Psi \mathrm{m}$ is essential as it drives ATP synthesis and maintains oxidative phosphorylation [18]. Dissipation of $\Delta \Psi \mathrm{m}$ induced by either $\mathrm{H}_{2} \mathrm{O}_{2}$ or FCCP could disturb mitochondrial ATP synthesis and lead to an overall decrease of ATP contents within oocytes. In addition, both $\mathrm{H}_{2} \mathrm{O}_{2}$ and FCCP could elicit significant $\mathrm{Ca}^{2+}$ signals, but oligmycin A could not, although all of them led to a decrease of ATP level and an impairment of spindle structure, further suggesting that $\mathrm{Ca}^{2+}$ is not a key factor in $\mathrm{H}_{2} \mathrm{O}_{2}$-induced spindle damage.

However, several studies suggested that deprivation of intracellular ATP by metabolic inhibitors appears not to influence cytoplasmic MT networks [7, 42]. In addition, depletion of intracellular ATP reduces the rate of MT disassembly, whereas addition of ATP increases it [45]. The difference between their data and ours may be attributed to the differences in cell types and cell cycles. Oocyte, as the largest cell in the body, needs sufficient ATP to support the transcription and translation processes during their growth and preparation for both nuclear and cytoplasmic maturation [22, 31]. Spindle formation and chromosome behavior depend on the expression and activity of motor proteins $[46,47]$. On average, conventional kinesic hydrolyses consume 125 ATPs per MT-binding event and therefore require sufficient local supplies of high-energy substrates. Therefore, we speculate that ATP, as the essential energy source for motor proteins, is one of the determinants for the formation of spindles. Further studies are needed to provide experimental evidence to support this notion.

In conclusion, the results from the present study indicate that mitochondria function is important for maintaining the integrity of spindles within MII oocytes, although we could not exclude the role of other oxidative targets such as tubulin [9] and GSH [28] in oxidant-induced spindle disruption. Owing to the high energy requirement in mouse MII oocytes, impairment of mitochondria function and decrease in mitochondria-derived ATP through PTP opening induced by oxidative stress can cause spindle disassembly. As maternal aging is associated with increased oxidative stress in human eggs [7], our results also provide a promising vista to explore the mechanisms of fertility aging.

\section{Acknowledgments}

This work was supported by the National Basic Research Program of China (2001CB5103), National Infrastructure Programme of Chinese Genetic Resources (2004DKA30490, 2005DKA21300) and the Initial Fund for Doctor, Shanxi Medical University Second Hospital.

\section{References}

1 Hassold TJ, Jacobs PA. Trisomy in man. Annu Rev Genet 1984; 18:69-97.

2 Hassold T, Hunt PA, Sherman S. Trisomy in humans: incidence, origin and etiology. Curr Opin Genet Dev 1993; 3:398-403.

3 Gaulden ME. Maternal age effect: the enigma of Down syndrome and other trisomic conditions. Mutat Res 1992; 296:69-88.

4 Bartmann AK, Romao GS, Ramos Eda S, Ferriani RA. Why do 
older women have poor implantation rates? A possible role of the mitochondria. J Assist Reprod Genet 2004; 21:79-83.

5 Chao HT, Lee SY, Lee HM, et al. Repeated ovarian stimulations induce oxidative damage and mitochondrial DNA mutations in mouse ovaries. Ann NY Acad Sci 2005; 1042:148-156.

6 Steuerwald N. Meiotic spindle checkpoints for assessment of aneuploid oocytes. Cytogenet Genome Res 2005; 111:256-259.

7 Tarin JJ. Potential effects of age-associated oxidative stress on mammalian oocytes/embryos. Mol Hum Reprod 1996; 2:717724.

8 Miquel J, Economos AC, Fleming J, Johnson JE Jr. Mitochondrial role in cell aging. Exp Gerontol 1980; 15:575-591.

9 Banan A, Choudhary S, Zhang Y, Fields JZ, Keshavarzian A. Oxidant-induced intestinal barrier disruption and its prevention by growth factors in a human colonic cell line: role of the microtubule cytoskeleton. Free Radical Biol Med 2000; 28:727-738.

10 Tarin JJ, Vendrell FJ, Ten J, Cano A. Antioxidant therapy counteracts the disturbing effects of diamide and maternal ageing on meiotic division and chromosomal segregation in mouse oocytes. Mol Hum Reprod 1998; 4:281-288.

11 Liu L, Trimarchi JR, Keefe DL. Thiol oxidation-induced embryonic cell death in mice is prevented by the antioxidant dithiothreitol. Biol Reprod 1999; 61:1162-1169.

12 Tarin JJ, Perez-Albala S, Cano A. Oral antioxidants counteract the negative effects of female aging on oocyte quantity and quality in the mouse. Mol Reprod Dev 2002; 61:385-397.

13 Agarwal A Allamaneni SS. Role of free radicals in female reproductive diseases and assisted reproduction. Reprod Biomed Online 2004; 9:338-347.

14 Crompton $\mathrm{M}$. The mitochondrial permeability transition pore and its role in cell death. Biochem J 1999; 341(Part 2):233-249.

15 Barritt JA, Brenner CA, Cohen J, Matt DW. Mitochondrial DNA rearrangements in human oocytes and embryos. Mol Hum Reprod 1999; 5:927-933.

16 Brenner CA, Wolny YM, Barritt JA, et al. Mitochondrial DNA deletion in human oocytes and embryos. Mol Hum Reprod 1998; 4:887-892.

17 Hsieh RH, Au HK, Yeh TS, et al. Decreased expression of mitochondrial genes in human unfertilized oocytes and arrested embryos. Fertil Steril 2004; 81(Suppl 1):912-918.

18 Gottlieb RA. Mitochondria and apoptosis. Biol Signals Recept 2001; 10:147-161.

19 Wilding M, Dale B, Marino M, et al. Mitochondrial aggregation patterns and activity in human oocytes and preimplantation embryos. Hum Reprod 2001; 16:909-917.

20 Van Blerkom J, Davis PW, Lee J. ATP content of human oocytes and developmental potential and outcome after in-vitro fertilization and embryo transfer. Hum Reprod 1995; 10:415-424.

21 Wilding M, De Placido G, De Matteo L, et al. Chaotic mosaicism in human preimplantation embryos is correlated with a low mitochondrial membrane potential. Fertil Steril 2003; 79:340-346.

22 Dumollard R, Marangos P, Fitzharris G, et al. Sperm-triggered $\left[\mathrm{Ca}^{2+}\right]$ oscillations and $\mathrm{Ca}^{2+}$ homeostasis in the mouse egg have an absolute requirement for mitochondrial ATP production. Development 2004; 131:3057-3067.

23 Eichenlaub-Ritter U, Vogt E, Yin H, Gosden R. Spindles, mitochondria and redox potential in ageing oocytes. Reprod Biomed Online 2004; 8:45-58.

24 Lawitts JA, Biggers JD. Culture of preimplantation embryos.
Methods Enzymol 1993; 225:153-164.

25 Baka SG, Toth TL, Veeck LL, et al. Evaluation of the spindle apparatus of in-vitro matured human oocytes following cryopreservation. Hum Reprod 1995; 10:1816-1820.

26 Cukurcam S, Sun F, Betzendahl I, Adler ID, Eichenlaub-Ritter U. Trichlorfon predisposes to aneuploidy and interferes with spindle formation in in vitro maturing mouse oocytes. Mutat Res 2004; 564:165-178.

27 Tarin JJ, Vendrell FJ, Ten J, et al. The oxidizing agent tertiary butyl hydroperoxide induces disturbances in spindle organization, c-meiosis, and aneuploidy in mouse oocytes. Mol Hum Reprod 1996; 2:895-901.

28 Zuelke KA, Jones DP, Perreault SD. Glutathione oxidation is associated with altered microtubule function and disrupted fertilization in mature hamster oocytes. Biol Reprod 1997; 57:1413-1419.

29 Xia T, Jiang C, Li L, et al. A study on permeability transition pore opening and cytochrome $c$ release from mitochondria, induced by caspase-3 in vitro. FEBS Lett 2002; 510:62-66.

30 Sugano N, Ito K, Murai S. Cyclosporin A inhibits $\mathrm{H}_{2} \mathrm{O}_{2}$-induced apoptosis of human fibroblasts. FEBS Lett 1999; 447:274-276.

31 Brevini TA, Vassena R, Francisci C, Gandolfi F. Role of adenosine triphosphate, active mitochondria, and microtubules in the acquisition of developmental competence of parthenogenetically activated pig oocytes. Biol Reprod 2005; 72:1218-1223.

32 Takahashi T, Takahashi E, Igarashi H, Tezuka N, Kurachi H. Impact of oxidative stress in aged mouse oocytes on calcium oscillations at fertilization. Mol Reprod Dev 2003; 66:143-152.

33 Liu L, Trimarchi JR, Keefe DL. Involvement of mitochondria in oxidative stress-induced cell death in mouse zygotes. Biol Reprod 2000; 62:1745-1753.

34 Chaube SK, Prasad PV, Thakur SC, Shrivastav TG. Hydrogen peroxide modulates meiotic cell cycle and induces morphological features characteristic of apoptosis in rat oocytes cultured in vitro. Apoptosis 2005; 10:863-874.

35 Mukherjee SB, Das M, Sudhandiran G, Shaha C. Increase in cytosolic $\mathrm{Ca}^{2+}$ levels through the activation of non-selective cation channels induced by oxidative stress causes mitochondrial depolarization leading to apoptosis-like death in Leishmania donovani promastigotes. J Biol Chem 2002; 277:24717-24727.

36 Satoh T, Enokido Y, Aoshima H, Uchiyama Y, Hatanaka H. Changes in mitochondrial membrane potential during oxidative stress-induced apoptosis in PC12 cells. J Neurosci Res 1997; 50:413-420.

37 Gonzalez A, Granados MP, Salido GM, Pariente JA. $\mathrm{H}_{2} \mathrm{O}_{2}$ induced changes in mitochondrial activity in isolated mouse pancreatic acinar cells. Mol Cell Biochem 2005; 269:165-173.

38 Fuller GM Brinkley BR. Structure and control of assembly of cytoplasmic microtubules in normal and transformed cells. J Supramol Struct 1976; 5:497(349)-514(366).

39 Berkowitz SA Wolff J. Intrinsic calcium sensitivity of tubulin polymerization. The contributions of temperature, tubulin concentration, and associated proteins. J Biol Chem 1981; 256:11216-11223.

40 Kiehart DP. Studies on the in vivo sensitivity of spindle microtubules to calcium ions and evidence for a vesicular calciumsequestering system. J Cell Biol 1981; 88:604-617.

41 Sun L Machaca K. Ca(2+)(cyt) negatively regulates the initiation of oocyte maturation. J Cell Biol 2004; 165:63-75. 
42 Bershasky AD, Gelfand VI. Role of ATP in the regulation of stability of cytoskeletal structures. Cell Biol Int Reprod 1983; 7:173-187.

43 Doenges KH. Assembly of non-neural microtubules in the presence of calcium ions. FEBS Lett 1978; 89:157-160.

44 Gorbsky GJ, Simerly C, Schatten G, Borisy GG. Microtubules in the metaphase-arrested mouse oocyte turn over rapidly. Proc Natl Acad Sci USA 1990; 87:6049-6053.
45 Bershadsky AD, Gelfand VI. ATP-dependent regulation of cytoplasmic microtubule disassembly. Proc Natl Acad Sci USA 1981; 78:3610-3613.

46 Heald R. Motor function in the mitotic spindle. Cell 2000; 102:399-402.

47 Hunter AW, Wordeman L. How motor proteins influence microtubule polymerization dynamics. J Cell Sci 2000; 113(Part 24):4379-4389. 